\title{
Optimization of Reinforced Concrete-Cum Masonry Construction
}

\author{
John K. Makunza \\ Department of Structural and Construction Engineering, University of Dar es Salaam, Dar es Salaam 35131, Tanzania
}

\begin{abstract}
In design and construction of low/high rise buildings, different forms of construction can be applied such as concrete shear wall structural system and framed structural system without or with masonry infill walls. At present, most buildings in East Africa are constructed as reinforced concrete framed structures with strong masonry infill, but during design, engineers assume that the masonry infill panels have zero contribution in offering load resistance. Due to the problem above, a study with an objective of finding out the influence of masonry panels on the properties of reinforced concrete infilled frame under vertical load has been done. Three types of models: reinforced concrete frame model, masonry model and reinforced concrete frame with masonry infill, were investigated using finite element technique. In additional to the finite element analysis, laboratory models were prepared and tested so as to check the validity of the analytical results. The obtained results have led to an establishment of a mathematical model which may be useful to the design engineers since masonry wall panels can now be considered as load bearing elements. Such consideration of frame together with masonry leads to an accurate and optimal design of the frame, resulting into lesser amount of reinforcement and geometrical properties of the frame.
\end{abstract}

Key words: Concrete, masonry infill, frame, design and finite-element.

\section{Introduction}

Most low/high rise buildings in East Africa are constructed as RC (reinforced concrete) framed structures with strong masonry infill, but in typical design procedures, structural engineers assume that the masonry infill panels have zero contribution in offering load resistance. Such assumption is a result of absence of an accurate and simple analytical model that takes into account the masonry contribution. This is due to the fact that no conclusive study has been done to ascertain the optimal benefit of reinforced concrete-cum-masonry construction. Thus, there is a need to determine the possible structural optimization of the reinforced concrete-cum-masonry construction.

Masonry walls have long been used as both load-bearing structural elements and architectural non-structural elements. In some cases, masonry walls fill the space within structural frames to separate

Corresponding author: John K. Makunza, Ph.D., research fields: building materials and structures. E-mail: makunzaj@gmail.com. interior spaces. Masonry infills are usually treated as non-structural elements in buildings and their interaction with the bounding frame is often ignored in design. Nevertheless, infill walls contribute strength to a structure and interact with the bounding frame. This interaction may be beneficial to the performance of the structure and it is obvious that infill panel increases the stiffness of bare frame. Although the infill panels significantly enhance both the stiffness and strength of the frame, their contribution is often not considered in design mainly because of the lack of knowledge of the composite behavior of the frame and the infill. This brings up the necessity of investigating the extent of how the interaction of masonry wall and reinforced concrete frame can change the property of the structural system.

Building frames can be constructed either from reinforced concrete or other materials like steel or timber. Concrete frames can be infilled or not infilled with masonry construction. If reinforced concrete frames infilled with masonry are properly designed 
and constructed together, they can carry and provide high resistance to the applied loads. But most engineers in the building design industry do consider the effect of concrete frame alone in carrying all the applied loads without considering the contribution of the infill masonry wall at all. Therefore, there is a need of investigating the significance contribution of infill masonry wall to the reinforced concrete frame when consideration of the composite behavior of the two is taken into account.

\section{Objectives}

The objective of the study was to carry out numerical simulation of the reinforced concrete frame model, masonry wall model and reinforced concrete frame with infilled masonry model, and investigate on the effect of the masonry infill in the frame using mathematical expression.

To ascertain the numerical results, laboratory tests were carried out with the following specific objectives:

(1) to establish the structural performance of solo masonry construction;

(2) to establish the parameters that govern the structural performance of solo reinforced concrete framed construction;

(3) to determine how the parameters in the two objectives above can be combined with view to optimizing the structural performance of RC-cum-Masonry construction while minimizing material inputs.

\section{Review on Reinforced Concrete Frame Analysis}

Reinforced concrete frames consist of horizontal elements such as beams and slabs and vertical elements such as wall and columns connected by rigid joints. These structures are cast monolithically, that is, beams and columns are cast together in order to act in unison. Reinforced concrete frames provide resistance to both gravity and lateral loads through bending in beams and columns and axial compression in columns.

Reinforced concrete frame construction is a method of building and designing structures, primarily using steel or reinforced concrete although they can be also constructed using laminated timber such as glulam. The connections between the columns and the beams are designed to be rigid and moment-resistant, which means they can carry both bending and axial forces. In most RC structures, a large stiffness is needed in order to limit structural deformation for service load conditions.

Because of these very strong and rigid joints, some of the bending moment in the beams is transferred to the columns. This means that the size of the beams can be reduced or the span can be increased for the same size. This makes a frame as very efficient construction technique to use for wide span buildings. They can be constructed with or without infill masonry walls, the infill walls can either be structural or non-structural construction members.

When analyzing a structure, the aim is to determine shear forces, axial forces and moments throughout the structural elements of a structure. The methods of frame analysis that are commonly used include the following:

- manual methods such as moment distribution or using solutions for standard frames;

- simplified manual methods of analyzing sub frames given in Code BS 8110 Part 1, Section 3.2.1 [1];

- computer plane frame programs based on the matrix stiffness method of analysis [2, 3].

All the methods above are based on elastic theory. BS8110 permits redistribution of up to $30 \%$ of the peak elastic moment to be made in frames up to four storeys. In frames over four storeys in height, where the frame provides the lateral stability, the redistribution is limited to $10 \%$ [4].

Modeling using computer analysis is recommended due to short time required to analyze a big structure and also storage of data plus fast corrections if errors 
are discovered. The general method applied is the stiffness method, and here it can be expressed in a simple way using a spring given in Fig. 1. Hence, based on Hooke's Law:

$$
F=K \cdot y
$$

where, $K=$ spring stiffness, $y=$ displacement.

Eq. (1) shows the equilibrium of the system, therefore, the displacement $y$ can be expressed by the equation:

$$
y=F / K
$$

If the actual displacement of the spring is $y=u$, then the internal force of the spring $P$ can be found by Eq. (3), thus:

$$
P=K \cdot u
$$

This stiffness method is extended and used to analyze for the internal actions of frames such as the one shown above. For a structure with a certain number of elements with $n$ degrees of freedom, the equilibrium of the structure is described by equations of similar form to Eq. (1). The equations are expressed in matrix form as:

$$
F_{(n \times 1)}=K_{(n \times n)} \cdot U_{(n \times 1)}
$$

where, $F_{(n \times 1)}$ is the load vector, $K_{(n \times n)}$ is the structure stiffness matrix composed of elements stiffness matrices $K_{e}$ and $U_{(n \times 1)}$ is the displacement vector.

The unknown displacements are determined by solving Eq. (4) into the following form:

$$
u=K^{-1} \cdot F
$$

where:

$$
\begin{aligned}
& K^{-1}=\text { inverse stiffness matrix; } \\
& F=\text { force vector; } \\
& u=\text { displacement vector. }
\end{aligned}
$$

Element forces $P$ : the moment, the axial force and shear force, are calculated using the equation:

$$
P=K_{\mathrm{e}} \cdot u=K_{\mathrm{e}} \cdot T^{T} \cdot u_{\mathrm{e}}
$$

where, $T$ is the transformation matrix and $u_{e}$ is the member displacement matrix depending on the degrees of freedom of the respective element.

The FEM (finite element method) [5] is a numerical solution to field problems in which a structure is divided into several elements, then connecting them at nodes. The analysis entails formation of a set of simultaneous algebraic equations which are solved by forward and backward eliminations using Gauss decomposition principle. The equations that govern FEM are essentially the same as Eqs. (3) to (6) above:

$$
K \cdot U=F
$$

where,

$F=$ array of applied forces (one for each degree of freedom);

$U=$ array of displacement (one for each degree of freedom) depending on shape functions;

$K=$ stiffness matrix (depending on geometry, material properties, and type of element);

The internal forces $P$ are calculated in the same manner using expression similar to Eq. (6).

Masonry walls are designed to bear both vertical loads as well as lateral loads. Vertical in-plane loads compression or tension are determined from dead, live and wind or uplift forces. Lateral out of plane loads on masonry walls are determined from wind forces actions. BS 5628 [6] states that the design vertical load of resistance of a wall must be greater than or equal to the design applied vertical load. The design vertical load of resistance for a straight wall without eccentricity (e), given in Fig. 2, is given by Eq. (8):

$$
P_{R d}=\frac{\beta \cdot t \cdot f_{k}}{\gamma_{m}}
$$

where:

$\gamma_{m}=$ partial safety factor for material strength, ranging from 2.5 to 3.5 [6], depending on the category of construction control, manufacturing and structural control;

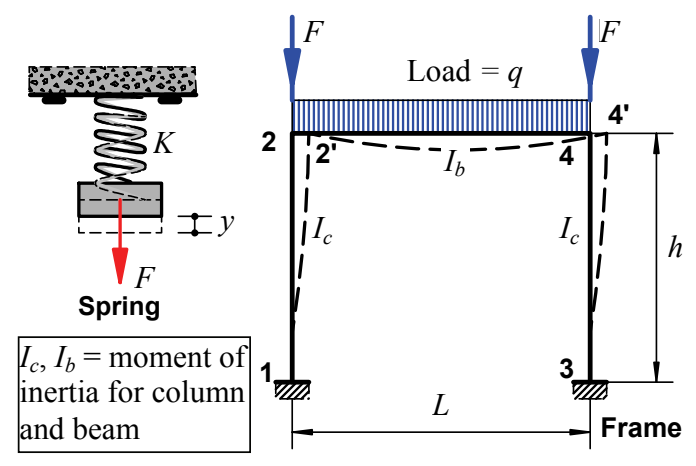

Fig. 1 Spring and frame configuration. 

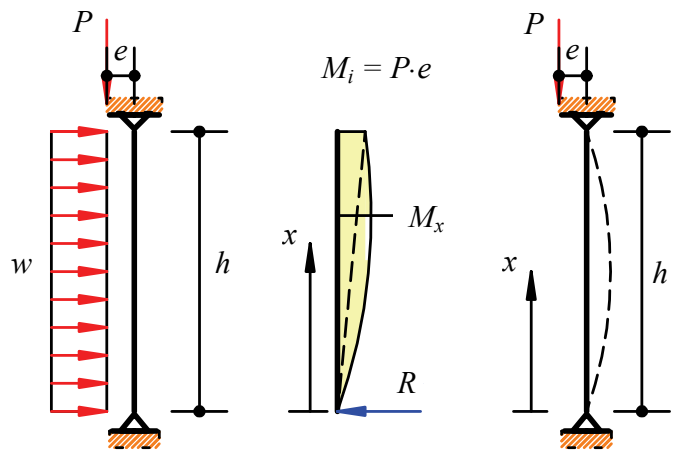

(a)
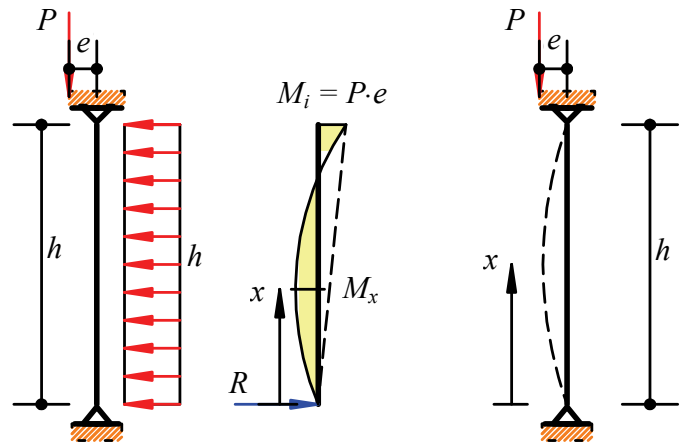

(b)

Fig. 2 Loads to masonry walls: (a) wind and axial load moments additive; (b) wind and axial load moments not additive.

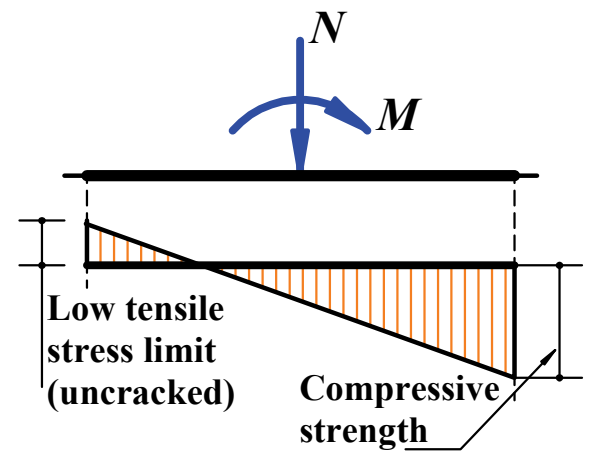

Fig. 3 Stress state in a wall.

$\beta=$ capacity reducing factor allowing for the effects of slenderness and eccentricity and is obtained from Table 4, BS 5628 Part 1;

$f_{k}=$ characteristic compressive strength of masonry as defined in Table 3 of BS 5628 Part 1;

$t=$ thickness of the wall.

If vertical and lateral loads are simultaneously applied, the wall is checked for both bending and axial load capacity. With reference to Fig. 2 [7], the moment is therefore given by:

$$
M_{x}=P \cdot e \cdot \frac{x}{h}+\frac{w(h-x) \cdot x}{2}
$$

For both cases, application of partial safety factors is taken into account so as to ensure safety of the structure.

The stress condition on the wall is depicted in Fig. 3, whereby part of the wall may be tension and the other part in compression, so:

$$
\sigma_{1,2}=\frac{P}{A} \pm \frac{M}{Z}
$$

where, $A=$ area of wall, $Z=$ section modulus of the wall.

\section{Investigation}

The investigation was done mainly using two approaches which include analytical investigation using the finite element method [2,3], in which three specimens: namely solo masonry, solo reinforced concrete frame and reinforced concrete frame with infill masonry, were modeled and analyzed. The reinforced concrete was converted into isotropic material using the modular ratio. The second approach was the laboratory investigation. Again, in this method, three model specimens of the same type as indicated above were prepared.

\subsection{Analytical Investigation}

\subsubsection{Masonry Model}

A masonry wall depicted in Fig. 3 was modeled using four noded 2D rectangular elements. Linear load of a magnitude of $40.0 \mathrm{kN} / \mathrm{m}$ was then applied on top of the wall. The stresses results obtained are shown in contour form in Fig. 4.

\subsubsection{Reinforced Concrete Frame Model}

Reinforced concrete frame model shown in Fig. 5 was meshed using rectangular 2D elements of four nodes each. The total number of nodes and elements were 72 and 35, respectively. The model was subjected to a vertical linear load of $40 \mathrm{kN} / \mathrm{m}$. All nodes at the bottom of the model were fixed. The results obtained are given in contours as depicted in Fig. 6. 


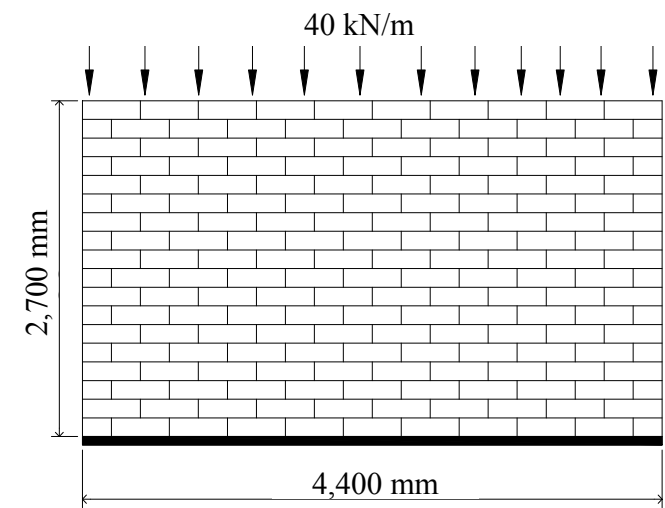

(a)

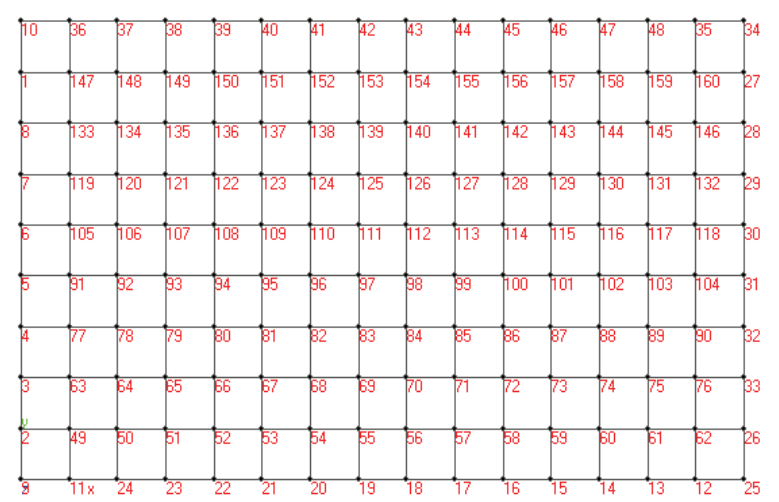

(b)

Fig. 4 Masonry model: (a) wall configuration; (b) mesh of the wall.
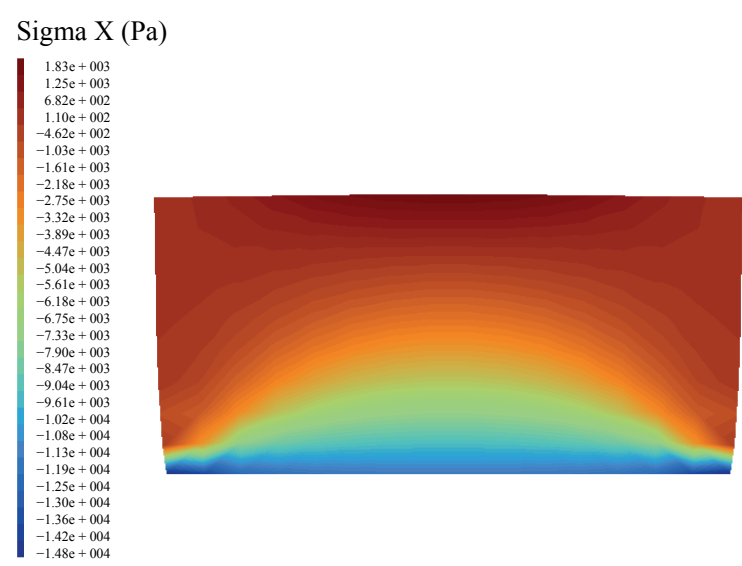

(a)

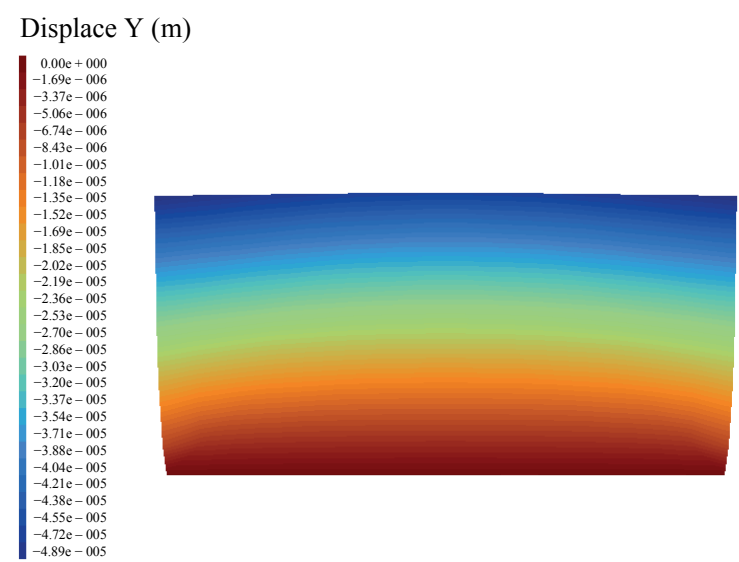

(b)

Fig. 5 Finite element deformed shape of masonry showing stress contour in: (a) $x$-axis; (b) $y$-axis.

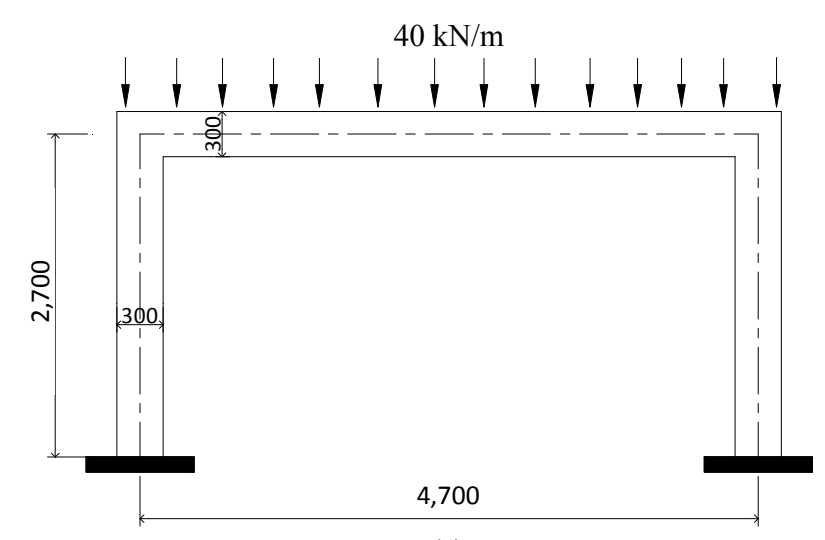

(a)

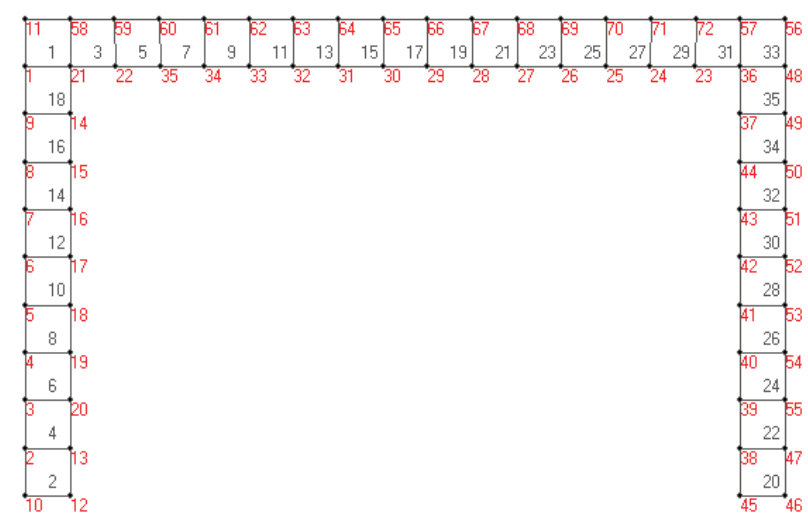

(b)

Fig. 6 RC frame model showing nodes and elements numbers: (a) frame configuration (units in mm); (b) mesh of the frame.

4.1.3 Reinforced Concrete Frame with Infill Masonry

Finally, the reinforced concrete frame infilled with masonry wall was modelled using the same type of elements and the same load intensity of $40.0 \mathrm{kN} / \mathrm{m}$ was applied as shown in Fig. 7. The analyzed results are shown in stress contours in Fig. 8.

\subsubsection{Selected Results}

The results obtained have shown that the infilled frame is stronger than both the bare concrete frame as 


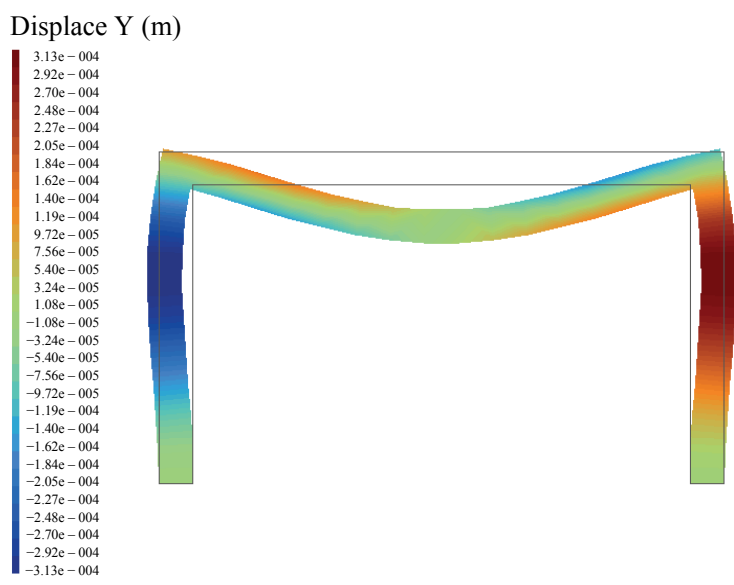

(a)

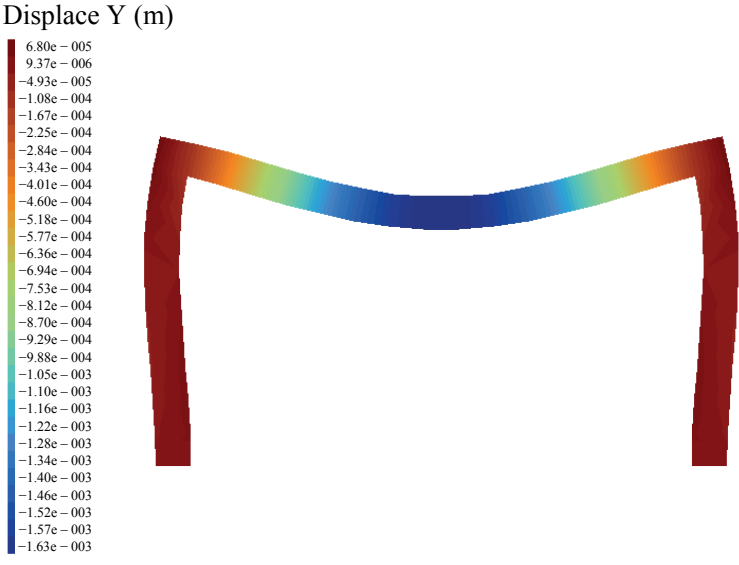

(b)

Fig. 7 Reinforced concrete frame showing stress contours in: (a) $x$-axis; (b) $y$-axis.

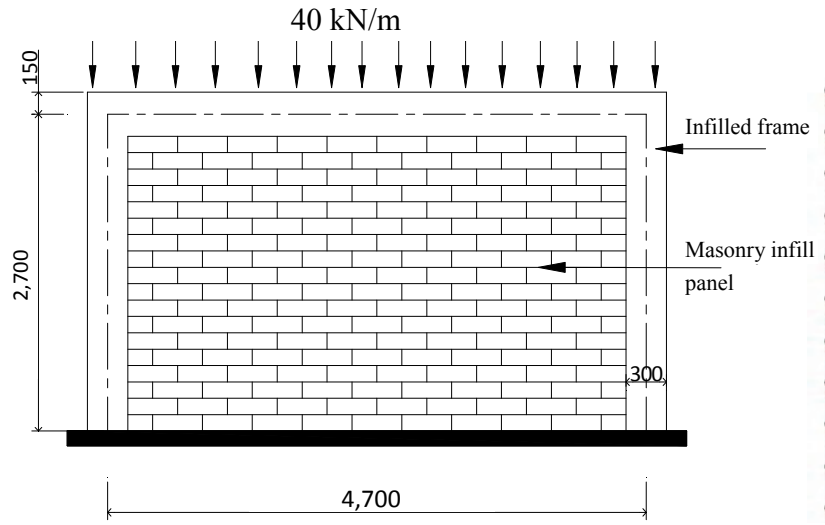

(a)

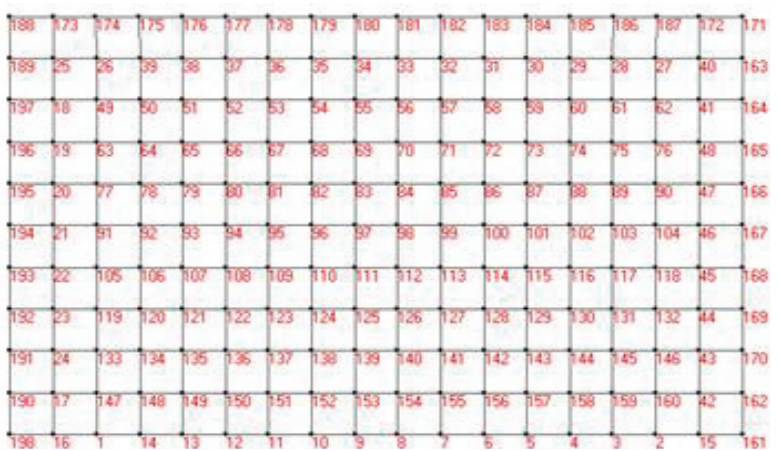

(b)

Fig. 8 Infilled frame and the associated mesh: (a) frame with infill masonry wall (units in mm); (b) elements mesh.

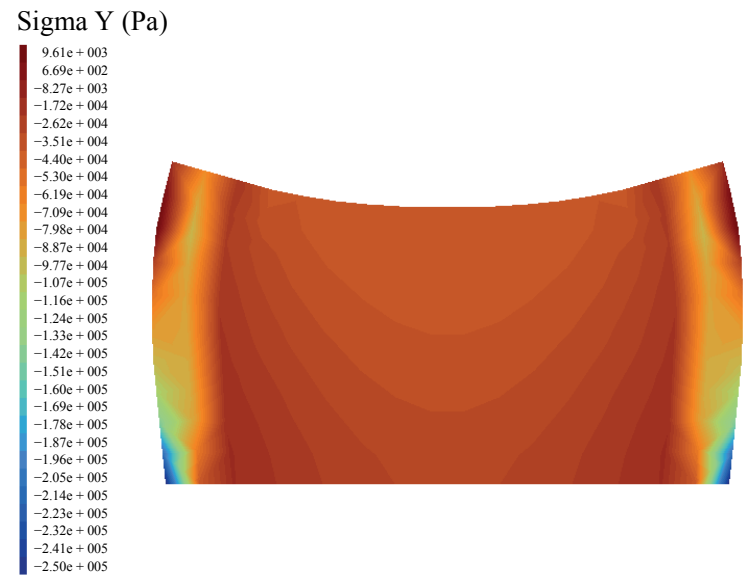

(a)

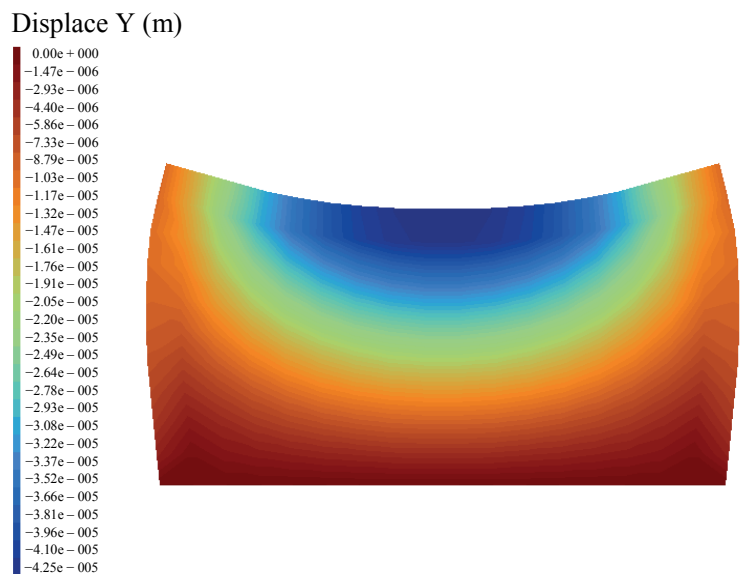

(b)

Fig. 9 Finite element deformed infilled frame showing stress contour along: (a) $x$-axis; (b) $y$-axis.

well as the infill wall. These results agree with the study done by Moldovan [8].

At prescribed points, stresses and displacements were taken in order to assess the relationship of the strength capacities of the studied models. Fig. 9 shows the stresses taken at similar points for the three models: masonry alone $(m)$, reinforced concrete frame $(f)$ and reinforced concrete frame with masonry 
infill $\left(f_{m}\right)$.

Moduli of elasticity for each model were determined and compared with the actual ones. Fig. 10 shows the results for the masonry $(m)$, for the concrete frame $(f)$ and finally for the reinforced concrete frame infilled with masonry $\left(f_{m}\right)$. It is observed that the reinforced concrete frame is almost at its final strength capacity, while the masonry and the infilled frame are still having significant reserve capacity that can be utilized in carrying extra high loads.

\subsection{Laboratory Investigation}

\subsubsection{Masonry Wall}

As in the case of analytical investigation, laboratory tests were also conducted in order to substantiate the numerical results. Three model pairs of $h / L$ ratio of 0.75 were prepared in the laboratory and tested respectively using universal compression test machine. For each of the models, the failure load and the respective displacements were recorded. The testing processes were indicated by Figs. 11 and 12. The obtained maximum loads are given in Table 1 .

\subsubsection{Reinforced Concrete Frame}

The concrete frame without infill masonry was tested as shown in Fig. 12a.

4.2.3 Reinforced Concrete Frame with Masonry Infill

The masonry infilled frame was tested and failed in a pattern, as shown in Fig. 12b.

\subsubsection{Equation Development}

Using experimental results from Sets 1 and 2 and FEM results from Fig. 9 together, an equation was successfully developed having the form:

$$
F_{f_{m}}=\alpha F_{m}+\beta F_{f}
$$

where:

$$
\alpha=-0.60 \text { and } \beta=1.58 \text {; }
$$

$F_{m}=$ ultimate strength of masonry wall;

$F_{f_{m}}=$ ultimate strength of infilled reinforced concrete frame;

$F_{f}=$ ultimate strength of reinforced concrete frame.
In the analysis for design, the ultimate design load for the reinforced concrete frame without infill masonry is normally $F_{f}$ given in Eq. (11) as the last term. But for a reinforced concrete frame with masonry infill, the actual design load is supposed to be $F_{f_{m}}$ in Eq. (11). Therefore, in order to utilize Eq. (11), the designer is required to determine both $F_{m}$ and $F_{f}$ stated above, then calculate for the final design load $F_{f_{m}}$.

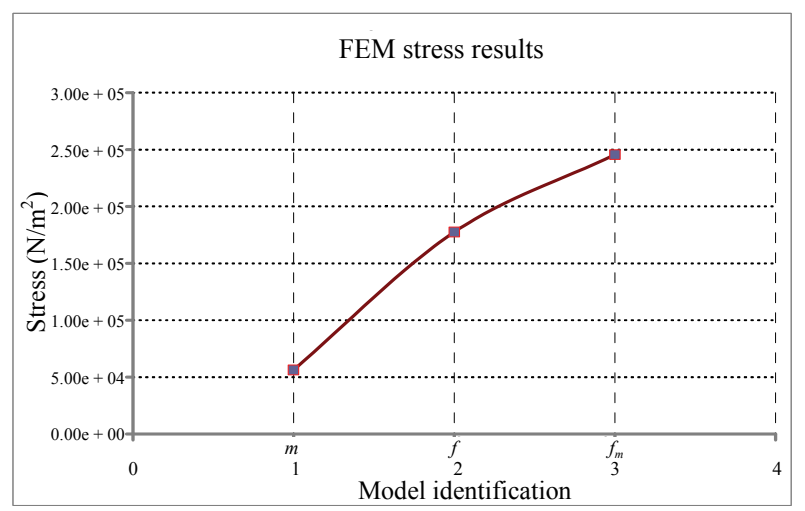

Fig. 10 Stresses vs. model type from FEM results.

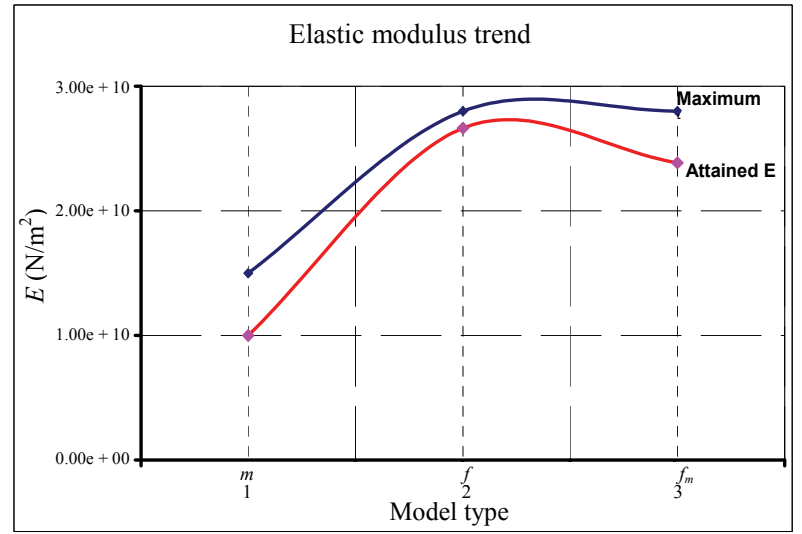

Fig. 11 Modulus of elasticity attained by each model.

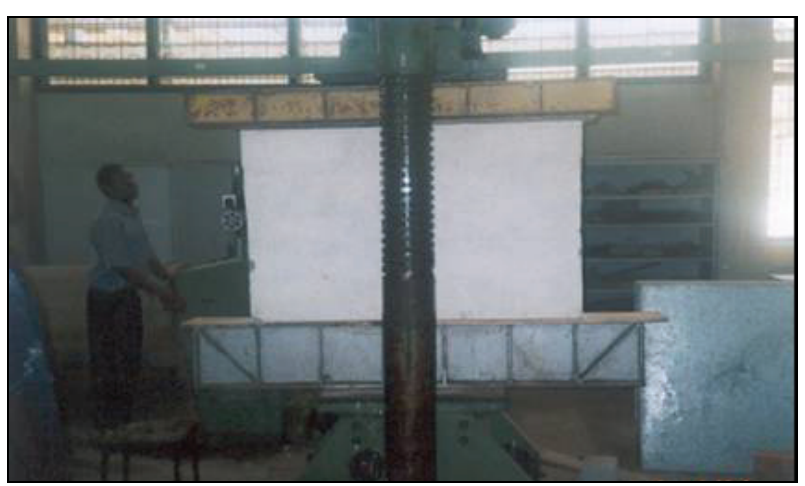

Fig. 12 Testing of the masonry wall. 


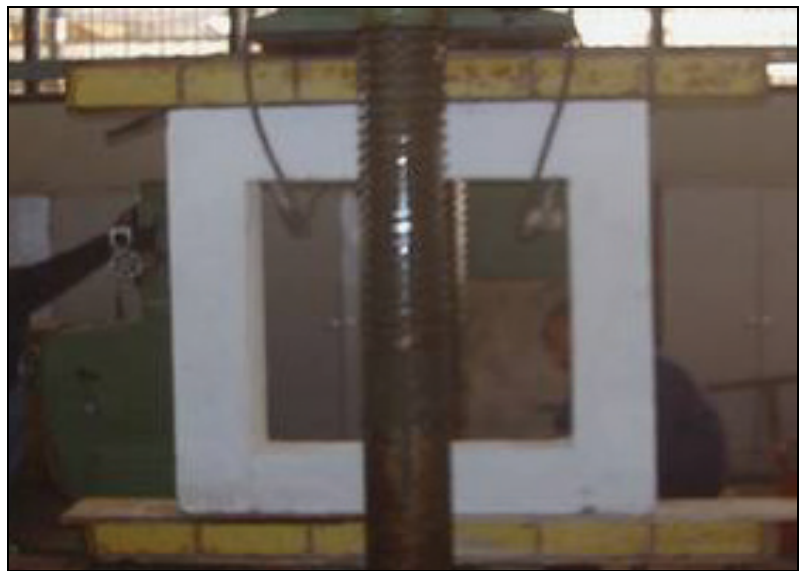

(a)

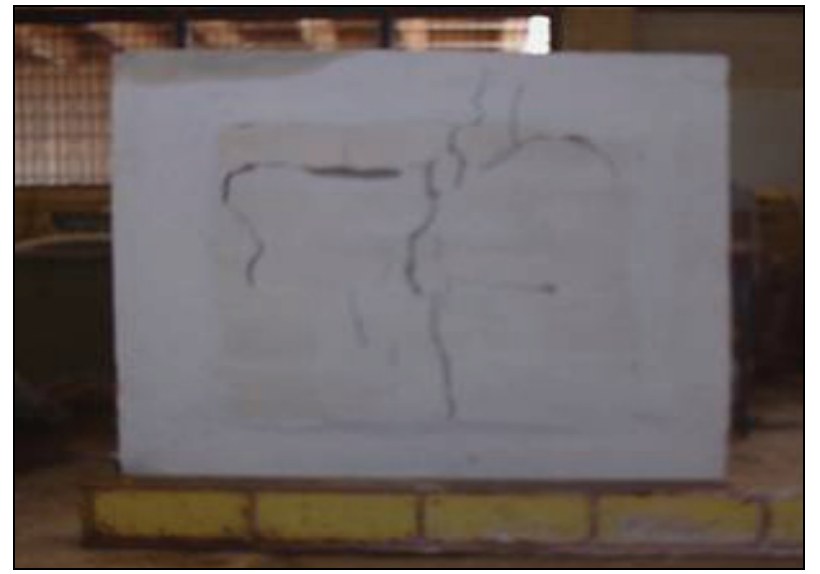

(b)

Fig. 13 Testing of models: (a) RC frame testing; (b) RC frame with masonry infill (after test).

Table 1 Summary of all laboratory test results.

\begin{tabular}{llllll}
\hline \multirow{2}{*}{ Type of model } & \multicolumn{2}{c}{ Ultimate load $F(\mathrm{kN})$} & & \multicolumn{2}{c}{$\begin{array}{c}\text { Deflection at ultimate load }\left(\times 10^{-2} \mathrm{~mm}\right) \\
\text { taken at top center of each specimen })\end{array}$} \\
\cline { 2 - 3 } \cline { 5 - 6 } & Set 1 & Set 2 & & Set 1 & Set 2 \\
\hline Masonry & 190 & 220 & & 525 & 490 \\
RC frame & 350 & 370 & 910 & 873 \\
RC frame infilled masonry & 430 & 460 & 1,040 & 996 \\
\hline
\end{tabular}

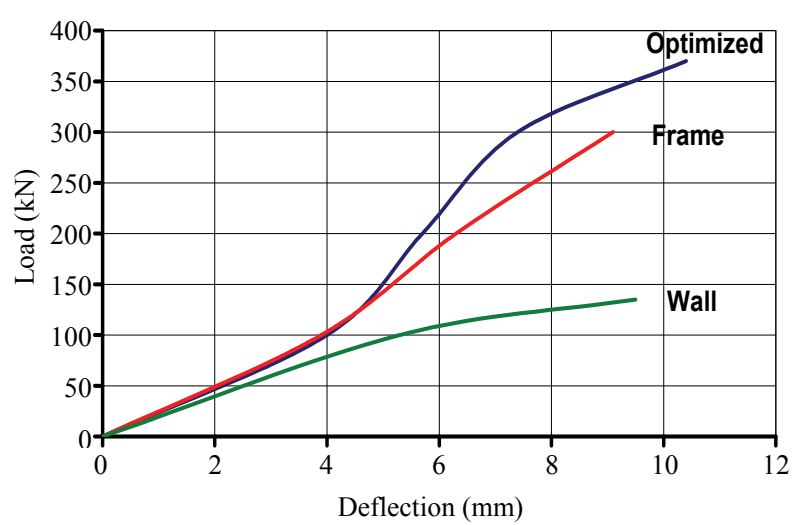

Fig. 14 Load-deflection diagram.

\subsubsection{Numerical Example}

An ultimate design load of a frame was observed to be $279 \mathrm{kN}$, and the ultimate load for the masonry infill wall was found to be $132 \mathrm{kN}$, as depicted in Fig. 13 . The task is to determine the ultimate design load for the optimized frame infilled with masonry wall.

The required design load of the whole system can now be determined using Eq. (11) above as follows:

$$
\begin{aligned}
& F_{m}=132 \mathrm{kN} \\
& F_{f}=279 \mathrm{kN}
\end{aligned}
$$

Therefore:

$$
F_{f_{m}}=(-0.6) \times 132+1.58 \times 279=361.62 \mathrm{kN}
$$

Alternatively, one may subtract the load that can be taken by the solo masonry wall from the gross load $F_{f_{m}}$, and then the remaining optimized load value $F_{f_{o p}}$ can be assigned to the frame, e.g.:

$$
F_{f_{o p}}=361.62-132=229.62 \mathrm{kN}<F_{f}
$$

The frame can now be designed using the optimized value that $F_{f_{o p}}$ bears which is less than the ultimate load capacity of the solo reinforced concrete frame resulting into less materials.

The design of solo masonry wall can be done by refereeing to BS 5628 Part 1 [6], while for solo reinforced concrete frame, the design may be done by using methods specified in the code of BS 8110: Part 1:1997 [1] or computer programs.

\section{Conclusions}

From both theoretical and experimental investigation results and made discussions, it is concluded that solo reinforced concrete structural framed system, although infilled with masonry, is highly practiced despite its high cost implication due 
to failure to optimize.

From the obtained results, it is concluded that the reinforced concrete with structural infill masonry has the highest ultimate load when compared with solo masonry model and reinforced concrete frame. This implies that the structural system can be optimized.

With regard to Fig. 9 and Table 1, it has been observed that the ultimate strength of the reinforced concrete frame infilled with structural masonry is a function of the individual strengths of the solo masonry wall and the solo reinforced concrete frame. This has been proven by establishing the relationship using Eq. (11).

From the study and conclusions which is made, the following points are recommended:

(1) The load that is imposed on the framed structure should be reduced by the amount that masonry walls can carry, then the rest should be assigned to the solo reinforced concrete frame. Eq. (11) should be applied in the calculations, thus:

$$
F_{f_{o p}}=(-0.6) F_{m}+1.58 F_{f}
$$

(2) A study on a frame with at least two spans is further recommended in order to explore the behavior of the whole system.

\section{References}

[1] BSI (British Standards Institution). 1997. Structural Use of Concrete, Part 1: 1997-Code of Practice for Design and Construction. BS 8110-1: 1997. London: BSI.

[2] Makunza, J. K. 2006. "Program for the Analysis of Plane Trusses." Tanzania Journal of Engineering and Technology 1 (1): 1-16.

[3] Wong, M. B. 2009. Plastic Analysis and Design of Steel Structures. Amsterdam: Butterworth-Heinemann.

[4] The Institution of Structural Engineers. 2000. Manual for the Design of Reinforced Concrete. London: The Institution of Structural Engineers.

[5] Buchanan, G. 1995. Finite Element Analysis. USA: Schaum's Outlines.

[6] BSI. 1985. Structural Use of Plain Masonry. BS 5628 Part 1. London: BSI.

[7] Hendry, A. W., Sinha, B. P., and Davies, S. R. 2004. Design of Masonry Structures. Third Edition of Load Bearing Brickwork Design. London: Taylor and Francis.

[8] Moldovan, M. D. 2012. "The Behavior of Reinforced Concrete Frames with Masonry Infills." Ph.D. thesis, Faculty of Civil Engineering, Technical University of Cluj-Napoca, Romania. 